\title{
K NIEKTORÝM NOVÝM NÁLEZOM Z DOBY LATÉNSKEJ NA SPIŠI
}

\author{
Marián Soják - Peter Fecko
}

DOI: https://doi.org/10.31577/szausav.2019.suppl.1.27

Keywords: Spiš region, non-destructive research in archaeology, selected archaeological findings, La Tène Period, analysis, spectral analyse, analogy

\begin{abstract}
Contribution to new La Tène Period archaeological findings from Spiš region
During the non-destructive archaeological prospection in the Spiš region the rare archaeological findings dated back to La Tène Period were obtained. In Jánovce-Machalovce the cross-shaped artefact (rose-shaped ring) was found, made of bronze, originally probably strung on the articulated central part of the horse snaffle bit. On the archaeological sites Spišský Hrhov and Spišské Podhradie the Celtic coins with the hump on their obverse were found - the Vel'ký Bysterec type. In Spišský Hrhov found silver tetradrachms were well-preserved. Among the others Slovak findings of this type, the aforementioned coin has the highest weight. In Spišské Podhradie silver-coated bronze didrachm was discovered. The tetradrachm of Vel'ký Bysterec type with the remains of inscription on its obverse - CAT or TAC - is also known from Spišský Hrhov. It is the only known tetradrachm with the inscription in Slovakia. Up-to-date only the didrachms of the mentioned type with inscriptions were known. The spectral analysis was performed on both coins. The iron knife with the ring at the end of its handle was found on Dreveník Hill in cadastral territory of Spišské Podhradie. It is dated to the $2^{\text {nd }}-1^{\text {st }}$ centuries BC based on the analogies from Slovakia and abroad. Two iron sickles are known from the archaeological site of the Púchov culture situated in cadastral area of Hrabušice. Their chronological classification within the La Tène Period is problematic.
\end{abstract}

\section{ÚVOD}

Za posledných desat' rokov sa na Spiši realizovalo niekol'ko rozsiahlejších archeologických výskumov. Uskutočnili sa najmä na viacerých úsekoch dialnice D1, zväčša s pozitívnymi výsledkami, pod vedením zamestnancov Archeologického ústavu SAV Nitra, ako aj viacerých ustanovizní a súkromných archeologických spoločností. Popritom sa vd’aka prísne kontrolovanej kooperácii so spolupracovníkmi AÚ SAV, pracoviska Spišská Nová Ves (dnes OZV - Spiš) podarilo na niektorých evidovaných lokalitách nájst' ojedinelé nálezy, z ktorých vyberáme zaujímavé exempláre, radené do doby laténskej (obr. 1).

\section{Jánovce-Machalovce (okr. Poprad), poloha Pod Hradiskom}

Centrálne hradisko púchovskej kultúry čiastočne skúmali už na konci 19. stor. (F. F. Rómer a najmä A. Münnich), intenzívne formou prieskumov od roku 1966 dodnes (F. Javorský, M. Soják). Práve neskoršie prieskumy naplno potvrdili opodstatnenost’ dôležitého postavenia v prvom rade púchovskej lokality v rámci regiónu Spiša a celej sídliskovej oikumeny zmienenej kultúry (Soják 2015, s literatúrou). Uvedené sídlisko má ústredné postavenie v západnej časti dolného Spiša, podobne ako nedaleko ležiaca Zelená hora v Hrabušiciach a hradný kopec Spišského hradu v Spišskom Podhradí a Žehre na východnom okraji dolného Spiša.

Lokalita v Jánovciach-Machalovciach sa skladá z opevneného Hradiska na výraznej terénnej dominante (kóta 683,1 m n. m.) a z dvoch podhradí, z nich najvýznamnejšie (Pod Hradiskom) leží na východnej strane hradiska (obr. 2: A). Práve z tejto polohy pochádza gro získaných nálezov z takmer celej doby laténskej a staršej doby rímskej. Z drobných kovových nálezov púchovskej kultúry sa odlišuje nasledujúci bronzový predmet. 

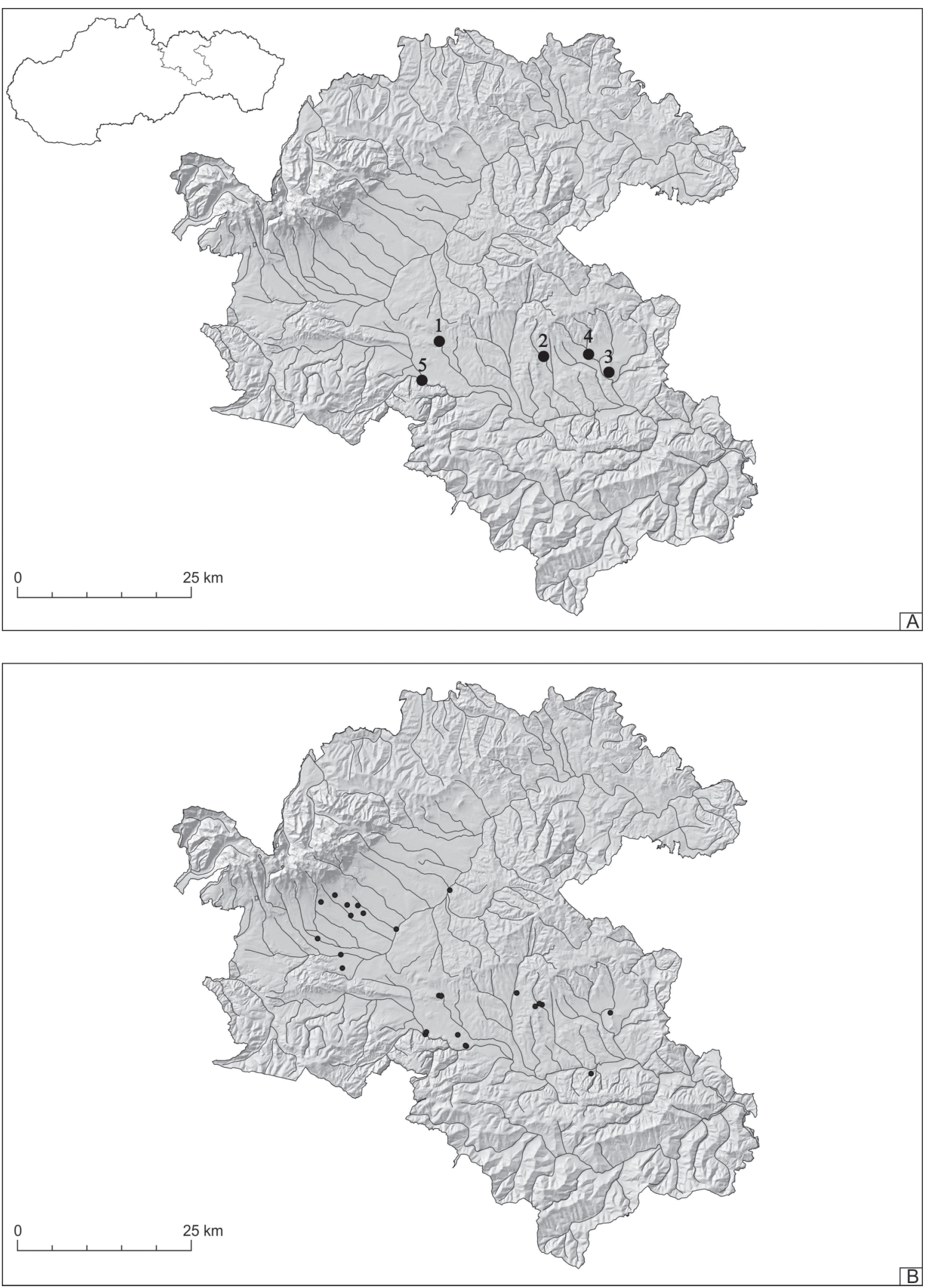

Obr. 1. A - región Spiša s lokalitami spomenutými v texte: 1 - Jánovce-Machalovce; 2 - Spišský Hrhov; 3 - Spišské Podhradie, poloha západný svah Dreveníka (Peklo); 4 - Spišské Podhradie, poloha Krížová hora (západný svah); 5 - Hrabušice; B - hustota osídlenia regiónu Spiš v dobe laténskej. 

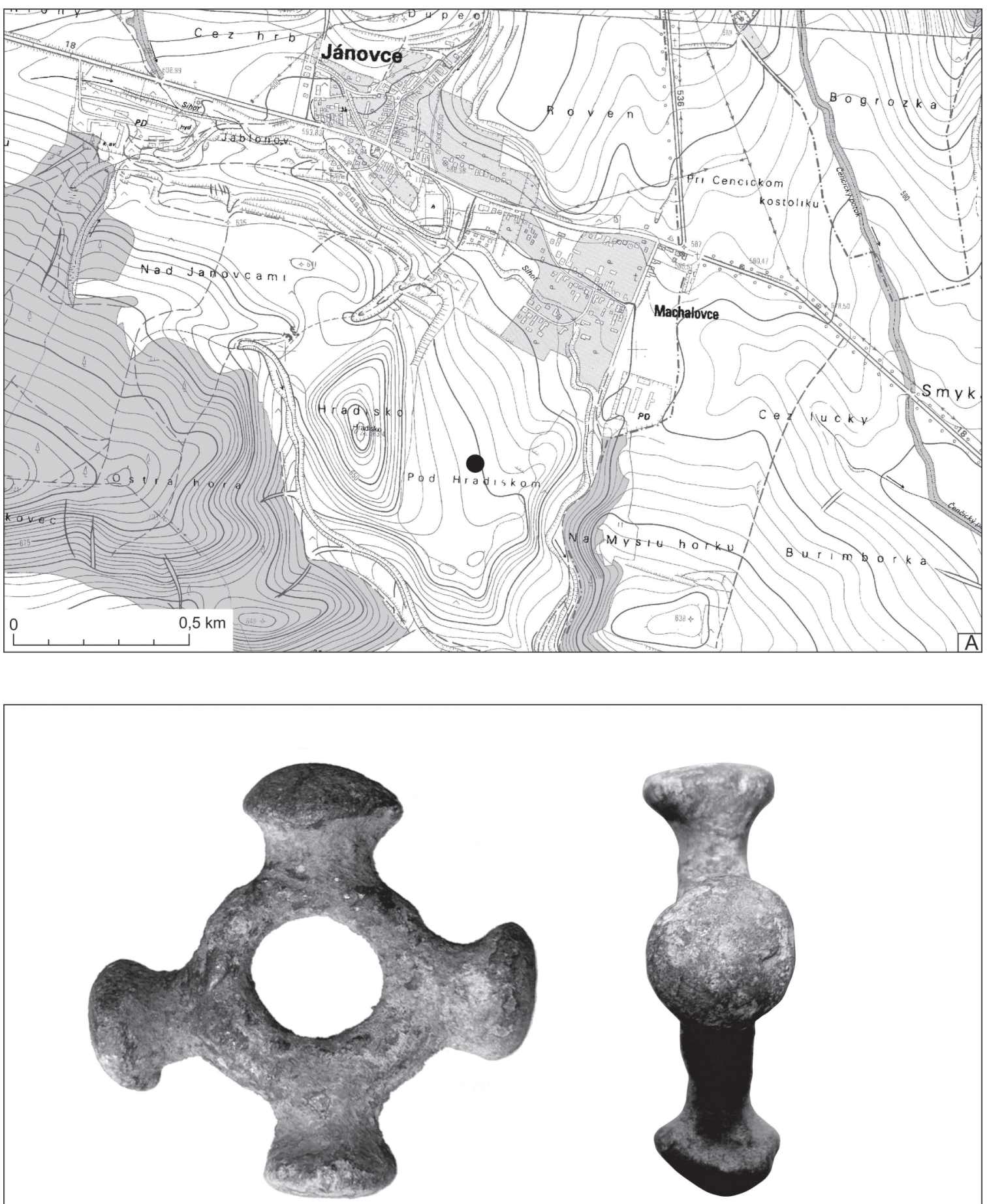

Obr. 2. Jánovce-Machalovce, poloha Pod Hradiskom. A - situovanie nálezu bronzovej návliečky na mape M 1 : 10 000; B - bronzový krúžok, resp. návliečka. 

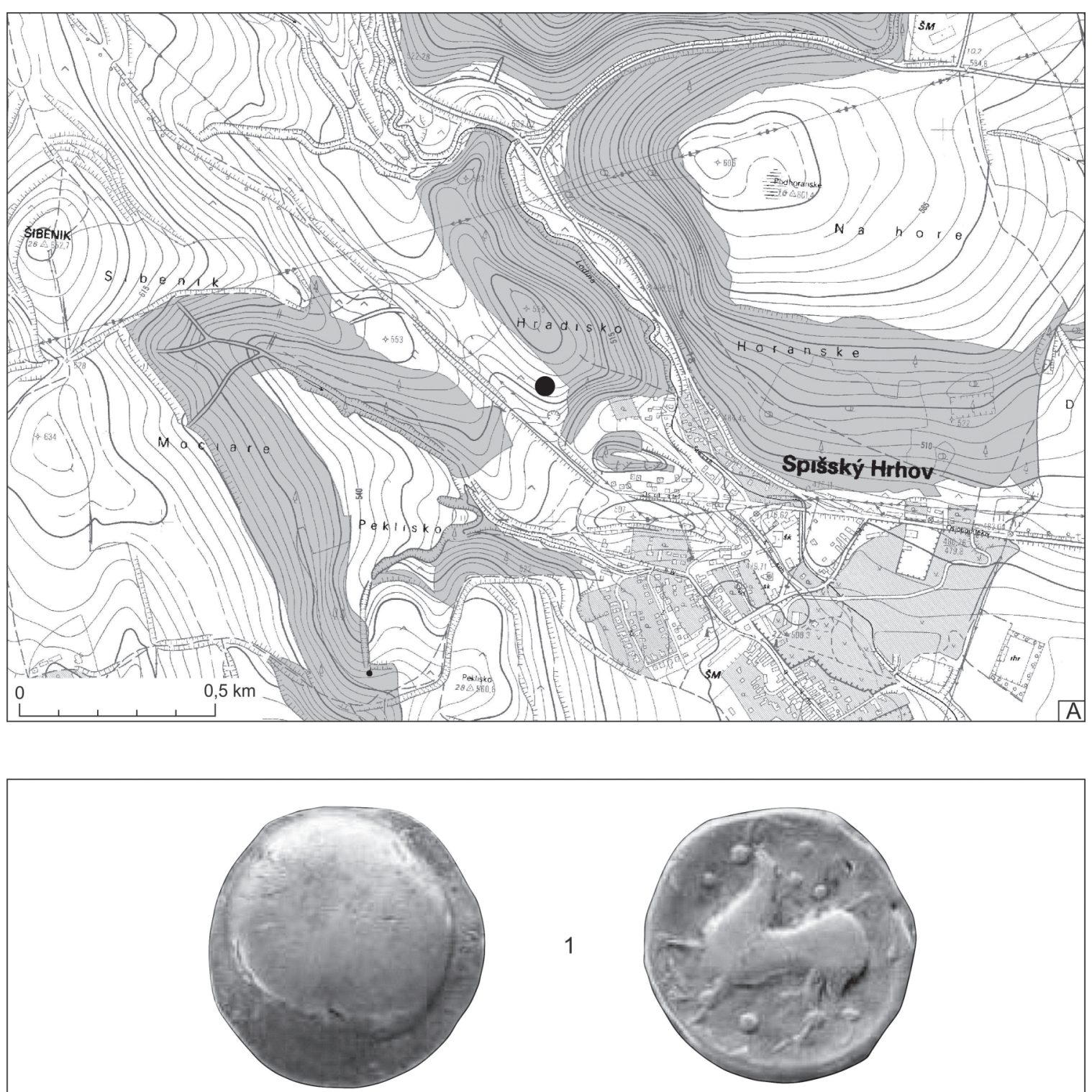

1
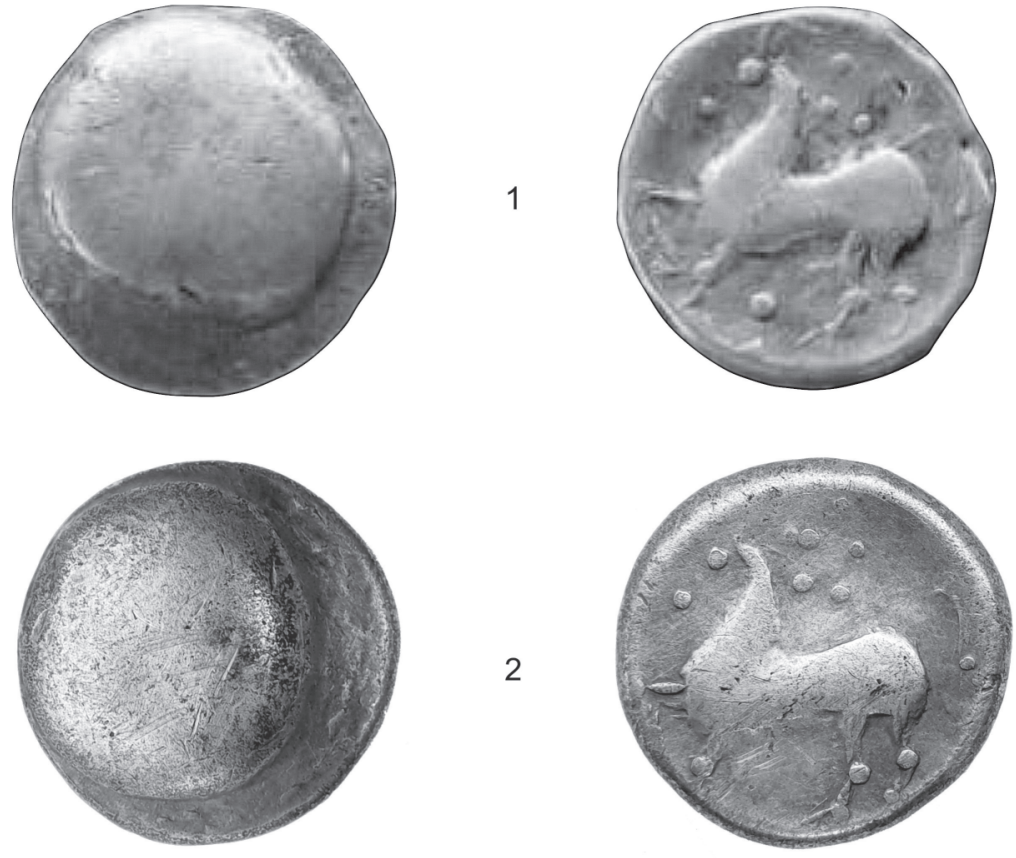

$3 \mathrm{~cm}$

Obr. 3. Spišský Hrhov, polohy Hradisko a Pod Hradiskom I. A - situovanie nálezu mince z roku 2018 v polohe Pod Hradiskom I na mape M 1 : 10 000; B - tetradrachmy typu Vel'ký Bysterec: 1 - nález z roku 2012; 2 - nález z roku 2018. 
- Kovanie (krúžok/návliečka) bronzové krížové/ružicové, s polgulovitými gombíkmi na ramenách a nevýrazne oválnym stredovým otvorom, max. rozpätie výrobku 32,5-33,5 mm, pr. otvoru 9-10 mm, hr. 5,5-10 mm, hmotnost’ 19,480 g (obr. 2: B). Spektrálna analýza ukázala 54,327 \% medi, 20,212 \% olova, 19,908 \% cínu a 3,491 \% železa.

\section{Spišský Hrhov (okr. Levoča), poloha Pod Hradiskom}

Rozsiahla sídlisková aglomerácia púchovskej kultúry leží nad severozápadným okrajom obce, nad cestou Levoča - Klčov a nad pravým brehom potoka Lodina. Pozostáva z opevnenej vyvýšeniny nazývanej Hradisko (550-570 m n. m.). Má dve stupňovité predhradia (vrchné a spodné), ako aj nížinné podhradie bez akejkolvek fortifikácie, ktoré býva označované ako poloha Pod Hradiskom I.

V roku 2010 realizoval AÚ SAV Nitra, pracovisko v Spišskej Novej Vsi výskum na dialnici D1 (úsek Jánovce - Jablonov), ktorý je z menšej časti publikovaný (Fecko/Soják 2012; Soják/Fecko 2013). Nálezový materiál, okrem iného s pozoruhodnou dvojdielnou emailovou sponou so štvorcovým rámikom na lučíku (koniec LTC1), umožňuje lokalitu datovat do mladšej fázy predpúchovského horizontu, resp. na počiatok púchovskej kultúry doby laténskej, t. j. na prelom 3./2., resp. začiatok 2. stor. pred n. 1. Toto datovanie je v zhode s výsledkami neskoršieho archeologického výskumu z roku 2012, ktorý vykonala Archeologická agentúra, s. r. o. (Matyasowszky a i. 2013).

V protiklade s chronologickým vymedzením púchovského náleziska je objav dvoch keltských mincí rovnakého typu (Vel'ký Bysterec), patriacich do kategórie severoslovenských keltských mincí s hrbolom na averze (Kolníková 2004). Prvá sa našla v roku 2012 na juhozápadnom svahu akropoly (Kolníková 2013a, 350 n.), druhá v roku 2018 počas prieskumu východnej časti podhradia Pod Hradiskom I (nepublikované; obr. 3: A).

- Tetradrachma typu Vel'ký Bysterec (nález z roku 2012), koniec 2. (?)-1. stor. pred n. 1.; Kelti, severné Slovensko, púchovská kultúra, A: nepravidelný hrbol' s ryhami a vrypmi v dôsledku úpravy razidla, okraj hladký, na jednom mieste s nevýraznými stopami písma v podobe CAT (alebo TAC); R: kôň v pokluse vlavo, hlava a nohy štylizované, hlavu znázorňuje puklička, nad ktorou je krátka vlnovka. Krk bez hrivy, nohy zakončené trojuholníkovitými kopytami, znázornený chvost. Nad koňom je pät pukličiek, pred ním jedna. Pod bruchom koňa je kolok v podobe pukličky a trojuholníka. Striebro, pr. 18-20 mm, hmotnost' 11,190 g, typ Velký Bysterec, variant B (obr. 3: B1; Kolníková 2013a).

- Tetradrachma typu Vel'ký Bysterec (nález z roku 2018), koniec 2. (?)-1. stor. pred n. 1.; Kelti, severné Slovensko, púchovská kultúra, A: oválny hrbol', okraj s viacerými nerovnostami v dôsledku úpravy razidla, bez náznakov písma; R: kôň v pokluse vlavo, hlava a nohy štylizované, hlavu znázorňuje puklička, bez vlnovky a hrivy na krku, nohy zakončené trojuholníkovitými kopytami, náznak chvosta. Nad koňom je pät pukličiek, pred ním jedna. Pod bruchom koňa sú náznaky nezachovaného kolku. Striebro, pr. 19-20 mm, hmotnost 11,680 g, typ Velký Bysterec, variant H? (avšak s náznakom chvosta!; obr. 3: B2; Kolníková 2004).

\section{Spišské Podhradie (okr. Levoča), západný svah Dreveníka (Peklo)}

Na západnom svahu kopca Dreveník (poloha Peklo) v nadmorskej výške 568 metrov, približne 50 až $60 \mathrm{~m}$ južne od kameňolomu (obr. 4: A). V roku 2019 sa podarilo v zmienenej polohe získat' ojedinelý železný predmet.

- Nôž železný, ukončenie rukoväte tvorí do kruhu roztepaný koniec tŕňa, s mierne prehnutým chrbtom, prehnutým ostrím a s ulomenou špičkou. Rozmery: celková dí. $200 \mathrm{~mm}$, dí. rukoväte $100 \mathrm{~mm}$, š. rukoväte $17 \mathrm{~mm}$, hr. rukoväte 5 $\mathrm{mm}$, dí. čepele $100 \mathrm{~mm}$, max. š. čepele $29 \mathrm{~mm}$, hr. chrbta čepele $3,3 \mathrm{~mm}$, hr. ostria $1 \mathrm{~mm}$, vonkajší pr. očka $23 \mathrm{~mm}$, vnútorný pr. očka $14 \mathrm{~mm}$, hr. tŕňa $4-5 \mathrm{~mm}$, hmotnost' 62,200 g (obr. 4: B).

\section{Spišské Podhradie, poloha Krížová hora (západný svah)}

Nález mince pochádza z polohy Krížová hora-západný svah (piate zastavenie krížovej cesty; obr. 5: A).

- Didrachma typu Velký Bysterec, 1. stor. pred n. l.; Kelti, severné Slovensko, púchovská kultúra, A: okrúhly hrbol', bez písma; R: kôň v pokluse vlavo, hlava a nohy štylizované; hlavu zobrazuje puklička s náznakom hrivy, nohy zakončené trojuholníkovými kopytami, nepatrne naznačený chvost. Nad koňom sú štyri pukličky, pred ním jedna. Pod bruchom koňa náznak kolku. Postriebrená a poolovená med, oválny strižok, pr. 14,8-18,4 mm, hmotnosł 5,270 g, typ Velký Bysterec, variant Aa (obr. 5: B; Kolníková 2004). 

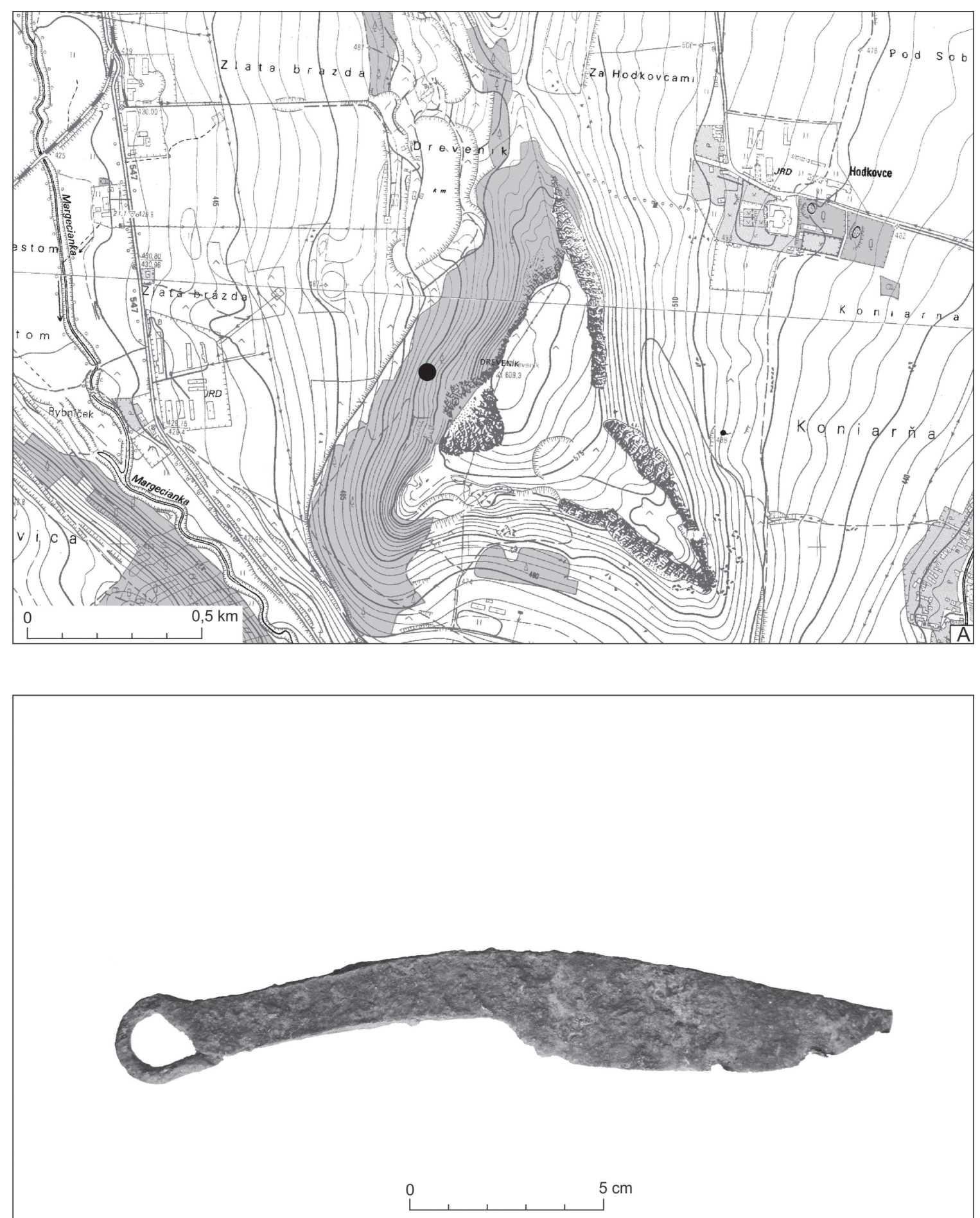

Obr. 4. Spišské Podhradie, poloha Dreveník, Peklo. A - situovanie nálezu železného noža na mape M 1 : 10000 ; B - železný nôž, ktorého ukončenie rukoväte tvorí do kruhu roztepaný koniec tŕňa. 


\section{Hrabušice (okr. Spišská Nová Ves), severovýchodný svah Zelenej hory}

Nálezy sú situované na severovýchodnom svahu Zelenej hory, kde sa v roku 2019 podarilo zberom z vývratov susediacich stromov získat dva kusy železných kosákov, ktoré možno chronologicky zaradit do obdobia púchovskej kultúry (obr. 6: A).

- Kosák železný s mierne ohnutým chrbtom a ukončený tŕňom na zasadenie do rukoväte, celková dí. $156 \mathrm{~mm}$, dí. tŕňa $33 \mathrm{~mm}$, š. tŕńa 9-11 mm, hr. tŕňa 3,4 mm, dí. čepele $120 \mathrm{~mm}$, max. š. čepele $25,5 \mathrm{~mm}$, hr. chrbta čepele 6,2 mm, hr. ostria 1,4 mm, hmotnost 40,600 g (obr. 6: B1).

- Kosák železný s mierne ohnutým chrbtom a ukončený tŕňom so zachovanou železnou manžetou, slúžiacou na pripevnenie rukoväti. Manžeta je prichytená k tŕňu pomocou železného nitu. Rozmery: dí. $115 \mathrm{~mm}$, dí. tŕňa $25 \mathrm{~mm}$, š. tŕńa $11 \mathrm{~mm}$, hr. tŕňa $1,5 \mathrm{~mm}$, dí. čepele $90 \mathrm{~mm}$, max. ̌s. čepele $19 \mathrm{~mm}$, hr. chrbta čepele $3,8 \mathrm{~mm}$, hr. ostria $1 \mathrm{~mm}$, š. manžety 19,4 mm, hr. manžety $1 \mathrm{~mm}$, hmotnost’ 20,600 g (obr. 6: B2).

\section{VYHODNOTENIE NÁLEZOV}

Bronzový výrobok z Jánoviec-Machaloviec nachádza blízke analógie $\mathrm{v}$ o niečo väčšom výrobku z Prašníka. T. Kolník (1999, 193-196) ho považuje za krížové kovanie, patriace k charakteristickým „kimmerským" predmetom, interpretovaným ako hlavice tzv. náčelníckych palíc (nem. Keulenzepter). Pravdou však je, že tvarová (pôdorysná) podobnost̉ je síce očividná (Chochorowski 1993, 135, obr. 16: 2), avšak hrúbka/výška hlavíc náčelníckych palíc je podstatne väčšia. Všeobecne sú takto interpretované artefakty masívnejšie, ako napríklad v prípade exemplára z Jánoviec-Machaloviec a tiež uvedeného predmetu z Prašníka. Priliehavejšia analógia, hoci zo železa, pochádza z lokality Udiča (Pieta 2008, 238, obr. 113: 12). V zhode $\mathrm{s} K$. Pietom tak opísaný výrobok pokladáme za ozubený krúžok či návliečku pôvodne navlečenú na kíbovom stredovom článku zubadla, teda za predmet súvisiaci s kantárom ako súčast’ postroja hlavy koňa (Pieta 2008, 237, 309). Datovanie týchto zmenšených ozubených koliesok do doby laténskej je najpravdepodobnejšie, aj ked' ich masívnejšie a hlavne podstatne hrubšie/vyššie tvarové predlohy sa objavujú už v dobe halštatskej; tieto mali predpokladané iné funkčné využitie.

Novoobjavený exemplár vel'kobystereckej tetradrachmy zo Spišského Hrhova (z roku 2018) sa podrobil na pôde AÚ SAV Nitra spektrálnej analýze (spektrometer XL3t-91027). Tá ukázala na 94,740 \% zastúpenie striebra, menší podiel medi $(3,230 \%)$, olova $(1,240 \%)$, zlata $(0,594 \%)$ a dalších stopových prvkov (železo - 0,159\%, platina -0,029 \%). Uvedené závery sú takmer totožné s výsledkami spektrálnych analýz rovnakých typov mincí z lokality Jánovce-Machalovce (Soják 2015, 27 nn.). Napokon na kvalitné striebro spišskohrhovskej razby poukazuje aj hmotnost’ objavenej mince, ktorá je dosial najvyššia (11,68 g!) spomedzi v súčasnosti známych exemplárov s hmotnostou pohybujúcou sa medzi 7,01-11,25 g (Kolníková 2013b, 19). Zaujímavé je, že uvedená vysoká hmotnost’ sa vyskytla v prípade tetradrachmy jedného z posledných vyčlenených variantov (H?), pri ktorých sú naopak príznačné nižšie hmotnosti (Kolníková 2004, 32). Z metrologických údajov vyplýva, že hmotnost̉ tetradrachiem typu Vel'ký Bysterec len málokedy presiahne 10,00 g (Kolníková 2004, $15 \mathrm{nn}$.). Z tohto pohladu má vysokú hmotnoste aj exemplár zo Spišského Hrhova, z výskumu z roku 2012 (11,190 g), ktorého variant B býva obvykle najtažší. Ten však skôr prekvapuje zobrazením averznej strany, na ktorej sú pod hrbolom nevýrazné stopy písma v podobe CAT (alebo TAC; Kolníková 2013a). Z doteraz publikovaných nálezov vel'kobystereckých mincí vyplýva, že uvedená skratka problematicky interpretovaných latinských písmen sa dosial' vyskytla výhradne na didrachmách, nie na tetradrachmách (Kolníková 2004, 14 n.; Soják 2012, obr. 1: 4; 2015, 26, 28, obr. 8, 9). Tým je opísaná razba zo Spišského Hrhova (z roku 2012) výnimočná.

Didrachma typu Velký Bysterec zo západného svahu Krížovej hory v Spišskom Podhradí je podla vyššie citovaného spektrometra takmer medená, čo vidno aj na prvý pohlad podla povrchu patinovaného do sivozelenej farby. Kov obsahuje 30,237 \% medi, 25,791 \% striebra, 24,742 \% olova a 15,110 \% cínu. Zo stopových prvkov sa objavili: $\mathrm{Fe}-2,400 \%, \mathrm{Ti}-0,707, \mathrm{Zn}-0,405 \%, \mathrm{Au}-0,163 \%$ a dalšie stopové prvky, ktoré obsahovali menej ako 0,100 \% (In, Cd, Pd, Rh, Ru, Mo, Nb, Pt, Ni). Pozoruhodný je pomerne vysoký podiel cínu, doložený dokonca v podobe takmer čisto cínovej razby (tetradrachmy typu Vel'ký Bysterec) v Jánovciach-Machalovciach. Zistené zastúpenie kovov sa však takmer zhoduje s predošlými analýzami z ostatne spomenutej lokality (Soják 2015, 25, 29, obr. 8: 6). Spoločným prvkom všetkých didrachiem typu Vel'ký Bysterec je porovnatelný pomer striebra a medi so značnou prímesou cínu, a tiež olova. Výhradne medený exemplár, ako pri typoch Liptovská Mara, sa dosial neobjavil. Didrachma na západnom svahu Krížovej hory predstavuje ojedinelý nález objavený v zázemí evidovaného púchovského osídlenia na spišskom hradnom kopci. 

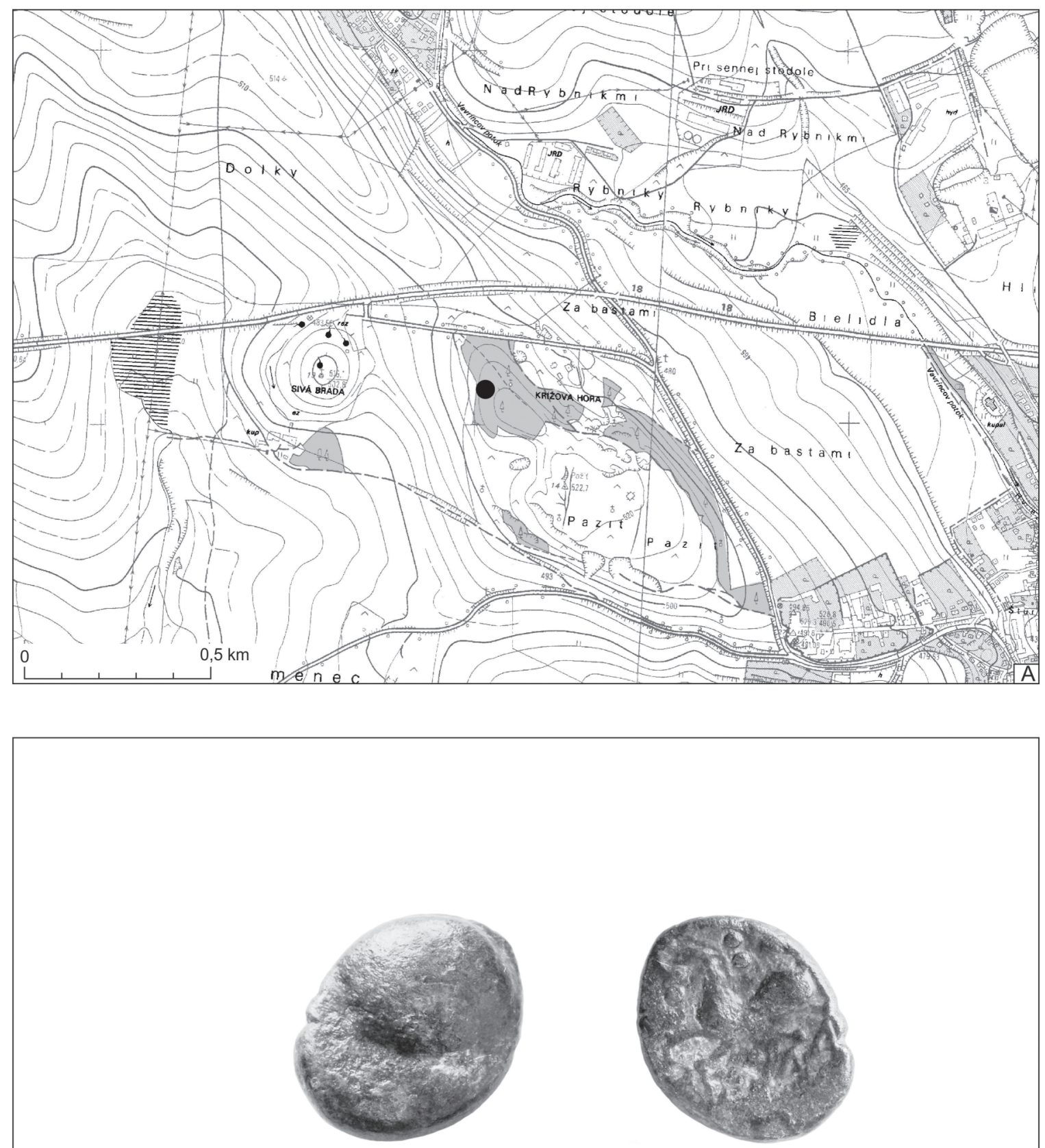

$3 \mathrm{~cm}$

Obr. 5. Spišské Podhradie, poloha Krížová hora, západný svah (piate zastavenie krížovej cesty). A - situovanie nálezu mince na mape M 1 : 10 000; B - didrachma typu Vel'ký Bysterec. 

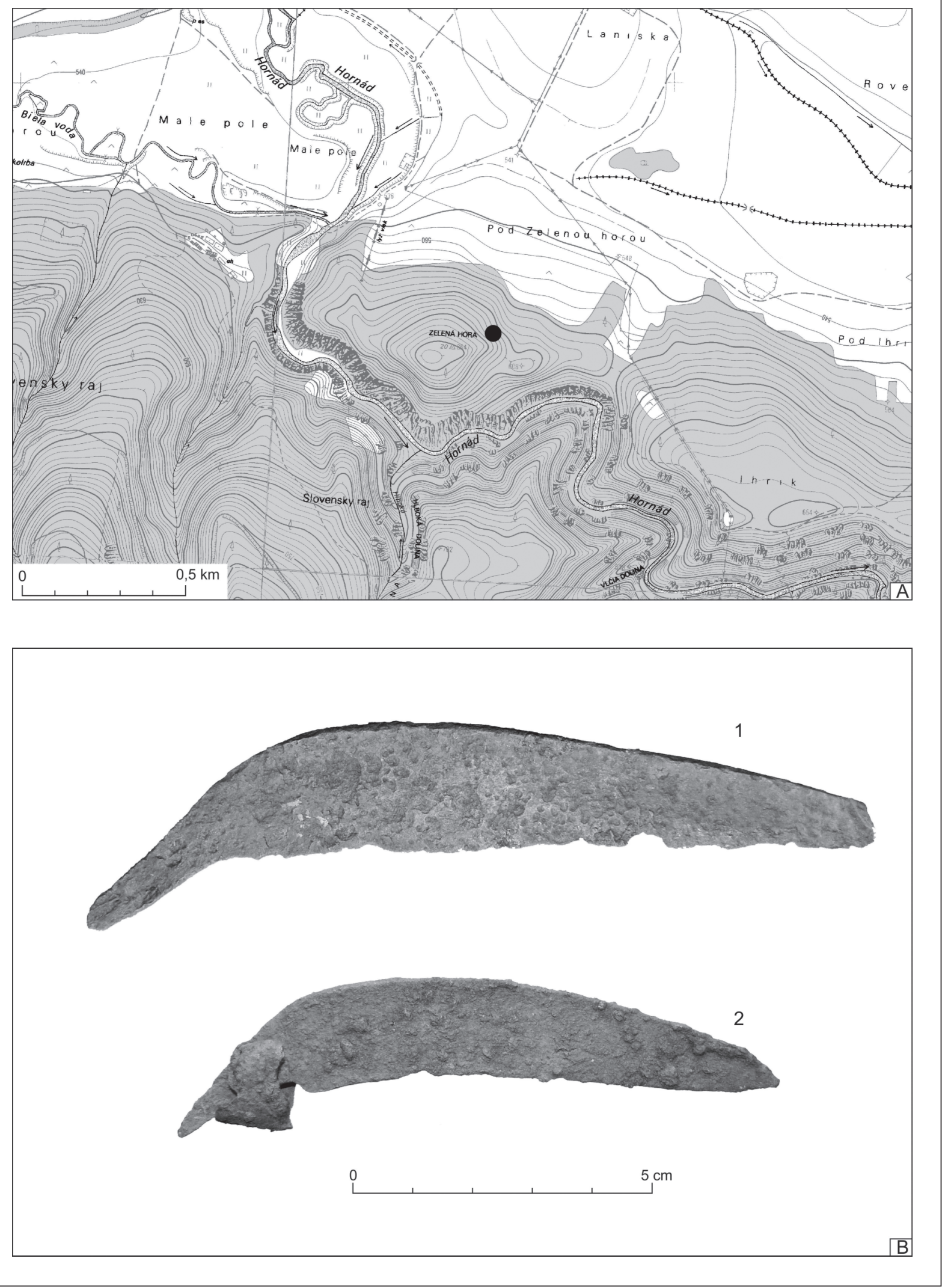

Obr. 6. Hrabušice, poloha severovýchodný svah Zelenej hory. A - situovanie nálezu železných kosákov na mape M 1 : 10 000; B - železné kosáky. 
Travertínový komplex Dreveník s novoobjaveným železným nožom je ako lokalita známy najmä výšinným sídliskom z eneolitu (badenská kultúra) a obdobia včasného stredoveku. Okrem toho sa tu našli nálezy zo staršej a mladšej doby bronzovej, staršej a mladšej doby železnej (Budinský-Krička 1961, 349, 350; Furmánek 1981; novšie s početnou literatúrou pozri Javorský 2011, 5-11; Soják 2007, 127 nn.). Prítomnost̉ nositelov púchovskej kultúry na Dreveníku dokladajú okrem iného aj nálezy nepočetných črepov, torzovite zachované bronzové spony rímskej konštrukcie a nepochybne aj nález keltskej mince - didrachmy vel'kobystereckého typu a rímska minca Trajána (Novotný/Kovalč́́k 1969, 9). Roztratený je depot Hadriánových mincí.

Nože patria k najčastejším nálezom na sídliskách a vyskytujú sa aj v hroboch ako súčast’ opaskovej garnitúry. Používali sa na univerzálne činnosti v kuchyni, pri stolovaní, spracovaní organických materiálov, hlavne dreva a kože, pri love a pravdepodobne i v boji (Pieta 2008, 275). Ich rukovät mohla byt ovinutá prúžkami kože pre pohodlné uchytenie (Jesenský 2015, 37). Pojednávaný nôž z Dreveníka s krúžkovou rukovätou sa pokladá vo všeobecnosti za mladší variant a je datovaný na rozhranie 2.-1. stor. pred n. 1., resp. LTD (Filip 1956, 175; Paulík 2008, 155). V našom prípade pravdepodobne nejde o tažký nôž, tzv. sekáč, ktorý je rozmerovo väčśí a dosahuje dĺžku vyše $40 \mathrm{~cm}$ a aké poznáme napríklad z Trenčianskych Teplíc (Pieta 2008, 153) alebo z bavorského Manchingu (Krön 1980, 303, obr. 234). Na slovenských lokalitách sa vyskytujú v značných počtoch a vo variabilných vel'kostiach a tvaroch (napr. Pieta 2008, obr. 69; 2014, 157). Ako analógie možno uviest’ napríklad nálezy z Trenčianskych Teplíc (Pieta 2008, obr. 69: 17), Plaveckého Podhradia (Pieta 2008, obr. 69: 20), Plaveckého Podhradia-Pohanskej (Paulík 1976, tab. L: 2, 4), Folkušovej-Necpál (Pieta 2014, obr. 10: 17), Udiče-Klapov (Veliačik/Moravčík 1992, obr. 59: 1), Devína (Plachá 1976, obr. 122: 5), resp. Jasenova-Vyšehradu (Remiášová 1978, obr. 125). Podobné nálezy poznáme tiež z územia Čiech, napríklad z lokality Bezdědovice (okres Strakonice), kde sú datované do druhej polovice 2. až tretej štvrtiny 1. stor. pred n. 1. (LTC2/D1, prípadne až začiatok LTD2; Michálek 1999, 55, napr. obr. 6: 607; 33: 4, 5; 34: 13; obr. 82), alebo z Hradiště nad Závistí (Pleiner a i. 1978, obr. 202: 4).

Kosáky slúžili predovšetkým na maloplošné vyžínanie trávnatých porastov. Svojím tvarom a vel'kostou sú značne variabilné. Staršie a mladšie kosáky doby laténskej sa od seba len tažko odlišujú (Pieta 2008, 224). Analógiu k druhému kosáku s manžetou na tŕni z Hrabušíc možno nájst' na lokalite Poniky-Ponická Huta a patrí pravdepodobne k stredolaténskemu horizontu osídlenia lokality - LTC1 (Pieta 2008, obr. 109: 13). Druhý hrabušický exemplár je typologicky podobný, o niečo väčší a bez manžety.

Vybrané laténske pamiatky hmotnej kultúry na príklade niektorých spišských nálezísk pochádzajú z nedeštruktívnych prieskumov aktívnych spolupracovníkov spišskonovoveského pracoviska AÚ SAV Nitra. Pokial' sú amatérski archeológovia pod drobnohladom profesionálov a pamiatky nie sú získané detektormi kovov, neraz je úspech zaručený. Je to aj prípad prezentovanej spolupráce, ktorou je možné nezištne získat’ a modernými spôsobmi (vrátane zamerania GPS) zdokumentovat zaujímavé artefakty.

\section{LITERATÚRA}

Budinský-Krička 1961

Fecko/Soják 2012

Filip 1956

Furmánek 1981

Chochorowski 1993

Javorský 2011

Jesenský 2015

Kolník 1999

Kolníková 2004

Kolníková $2013 a$
V. Budinský-Krička: Slovanské osídlenie na severovýchodnom Slovensku. Slovenská archeológia 9, 1961, 347-390.

P. Fecko/M. Soják: Sídlisko púchovskej kultúry v Spišskom Hrhove na Spiši. In: G. Březinová/B. Varsik (ed.): Archeológia na prahu histórie. K životnému jubileu Karola Pietu. Nitra 2012, 247-262.

J. Filip: Keltové ve střední Evropě. Praha 1956.

V. Furmánek: Záchranný archeologický výskum na Dreveníku. Archeologické výskumy a nálezy na Slovensku v roku 1980, 1981, 64-67.

J. Chochorowski: Ekspansja kimmeryjska na tereny Europy środkowej. Kraków 1993.

F. Javorský: Kronika písaná v zemi. In: F. Žifčák (zost.): Kronika mesta Spišské Podhradie. Košice 2011, 5-11.

M. Jesenský: Kelti na Liptove. In: M. Jesenský a kolektív: Kelti. Vel’ká kniha o Keltoch v Žilinskom kraji. Martin 2015, 24-39.

T. Kolník: Unikátne nálezy z Prašníka. Študijné zvesti AÚ SAV 33, 1999, 193-196. E. Kolníková: Severoslovenské keltské mince s hrbol’om na averze. Slovenská numizmatika 17, 2004, 11-52.

E. Kolníková: Odborný posudok nálezu mince z katastra obce Spišský Hrhov, okr. Levoča. In: Matyasowszky a i. 2013, 350, 351. 
Kolníková 2013 b

Krön 1980

Matyasowszky a i. 2013

Michálek 1999

Novotný/Kovalčík 1969

Paulík 1976

Pieta 2008

Pieta 2014

Plachá 1976

Pleiner a i. 1978

Remiášová 1978

Soják 2007

Soják 2012

Soják 2015

Soják/Fecko 2013

Veliačik/Moravčík 1992
E. Kolníková: Keltská razba mincí na Slovensku a jej surovinové zdroje. In: D. Haas Kianička (zost.): Baníctvo a mincovníctvo v dejinách Slovenska. Zborník príspevkov z medzinárodného numizmatického seminára. Kremnica 2013, 7-24.

P. Krön: Die Kelten in Mitteleuropa. Salzburg 1980.

F. Žák Matyasowszky/A. Žitňan/D. Krajčiová/L. Chmelo: P001 - Dialnica D1 Jánovce - Jablonov, II. úsek, km 9,0-18,5. Lokalita 13, Spišský Hrhov, poloha Pod Hradiskom. Bratislava 2013. Rukopis.

J. Michálek: Keltský poklad z Bezdědovic na Blatensku. Blatná - Strakonice 1999.

B. Novotný/R. M. Kovalčík: Katalóg archeologických pamiatok Spiša 1. Vlastivedná miestnost' Spišské Podhradie. Bratislava 1969.

J. Paulík: Keltské hradisko Pohanská v Plaveckom Podhradí. Bratislava 1976.

K. Pieta: Keltské osídlenie Slovenska. Mladšia doba laténska. Nitra 2008.

K. Pieta: Hradiská vo Folkušovej-Necpaloch a Blatnici. Juhovýchodné prvky v púchovskej kultúre. Slovenská archeológia 62, 2014, 125-165.

V. Plachá: Výsledky výskumu na hrade Devín v roku 1975. Archeologické výskumy a nálezy na Slovensku v roku 1975, 1976, 186-188.

R. Pleiner a kolektiv: Pravěké dějiny Čech. Praha 1978.

M. Remiášová: Pokračovanie výskumu na lokalite Vyšehrad. Archeologické výskumy a nálezy na Slovensku v roku 1977, 1978, 205, 206.

M. Soják: Osídlenie spišských jaskýn̆ od praveku po novovek. Nitra 2007.

M. Soják: Nové nálezy keltských mincí zo Spiša. Denarius 2, 2012, 3-7.

M. Soják: Lokalita Jánovce-Machalovce v kontexte nových numizmatických nálezov z doby laténskej. Numizmatika 25, 2015, 22-34.

M. Soják/P. Fecko: Výskum lokality z doby laténskej v Spišskom Hrhove v roku 2010 (predbežné výsledky). In: J. Gancarski (ed.): Transkarpackie kontakty kulturowe w okresie lateńskim, rzymskim i wczesnym średniowieczu. Krosno 2012, 11-30. L. Veliačik/J. Moravčík: Prieskum niektorých výšinných polôh v okrese Považská Bystrica. Archeologické výskumy a nálezy na Slovensku v roku 1990, 1992, 99, 100.

\title{
Contribution to new La Tène Period archaeological findings from Spiš region
}

\author{
Marián Soják - Peter Fecko
}

Summary

Cooperation with amateur archaeologists under strict supervision of the professionals is often successful and yielding interesting artefacts of material culture. It is also the case of Slovak Academy of Sciences Institute of Archaeology branch Spišská Nová Ves, where such cooperation takes place for about ten years. From selected archaeological sites, some of the remarkable findings that can be dated to the La Tène Period are presented in our paper.

Archaeological site Jánovce-Machalovce yielded very interesting isolated find regarded as cross-shaped ring/sleeve made of bronze, originally probably strung on the articulated central part of the horse snaffle bit. Similar forms can be found among the so-calles Cimmerian bronzes, where they are considered as a part of the chief's stick. Our exemplar, as well as similar ones made of bronze and iron (Prašník, Udiča), are considerably smaller and thinner, and therefore we suggest their use as the parts of the horse snaffle bit.

The silver tetradrachm coin of Vel'ký Bysterec type was found in extramural settlement of hillfort dated to the Púchov culture in Spišský Hrhov. It is the second coin of this type from this archaeological site. The newly discovered specimen is one of the heaviest tetradrachms of Vel'ký Bysterec type found in Slovakia until now (11.680 g). The results of spectral analysis shows following content of the metals: silver $94.740 \%$, copper $3.230 \%$, lead $1.240 \%$, gold $0.594 \%$ and other trace elements as iron $0.159 \%$, platinum $0.029 \%$. These results are almost identical with the results of the spectral analysis of the same types of coins found on archaeological site Jánovce-Machalovce. The first one of tetradrachms coin of Vel'ký Bysterec type found in Spišský Hrhov is worth to mention because under the hump on its obverse the rest of the inscription in a form of CAT or TAC is preserved. It is the first specimen of this type of coins with inscription in Slovakia ever. Only the didrachms of Vel'ký Bysterec type with inscription have been known until now.

Interesting artefacts were found on Dreveník Hill and on the western slope of Krížová hill, both in the cadastral territory of Spišské Podhradie. The first artefact is massive iron knife with the ring at the end of the handle, which is 
generally considered to be the younger variant of such knives, dated to the $2^{\text {nd }}-1^{\text {st }}$ centuries $\mathrm{BC}$, respectively to Lt D. On the second archaeological site the silver-coated bronze didrachm of Vel'ký Bysterec type was found. It was discovered close to the registered hilltop settlement of Púchov culture on Spiš Castle.

On the north-eastern slope of Zelená hora hill in the cadastral area of Hrabušice, two iron sickles were found on the spot where two trees were blew down. Their closer cultural assessment within the La Tène Period is problematic (from the middle to the late La Tène Period).

Fig. 1. A - Spiš region with the archaeological sites mentioned in the text: 1 - Jánovce-Machalovce; 2 - Spišský Hrhov; 3 - Spišské Podhradie, site western slope of Dreveník (Peklo); 4 - Spišské Podhradie, site Krížová hora (western slope); 5 - Hrabušice; B - density of settlement in the Spiš region during La Tène Period.

Fig. 2. Jánovce-Machalovce, archaeological site Pod Hradiskom. A - location of the bronze sleeve on the map with scale M 1 : 10 000; B - bronze ring/sleeve.

Fig. 3. Spišský Hrhov, archaeological sites Hradisko and Pod Hradiskom I. A - position of the coin found in 2018 on the archaeological site Pod Hradiskom I on the map with scale 1: 10 000; B - tetradrachm coins of Vel'ký Bysterec type: 1 - archaeological finding discovered in 2012; 2 - archaeological finding discovered in 2018.

Fig. 4. Spišské Podhradie, archaeological site Dreveník, Peklo. A - location of the iron knife on the map with scale M 1 : 10 000; B - iron knife, whose the end of the handle is finished with the pike peened to the ring shape.

Fig. 5. Spišské Podhradie, archaeological site Krížová hora hill, west slope (the fifth station of the Way of the Cross). A location of the coin on the map with scale M 1 : 10 000; B - didrachm coin of Velký Bysterec type.

Fig. 6. Hrabušice, archaeological site north-eastern slope of the Zelená hora hill. A - location of the iron sickles on the map with scale M 1 : 10 000; B - iron sickles.

PhDr. Marián Soják, PhD.

Archeologický ústav SAV, OZV - Spiš Mlynská 6

SK - 05201 Spišská Nová Ves

sojak@ta3.sk
Mgr. Peter Fecko

Archeologický ústav SAV, OZV - Spiš

Mlynská 6

SK - 05201 Spišská Nová Ves

feckop@gmail.com 